\title{
Erratum to: Imaging in rheumatology: ultrasafe + ultrasure $=$ ultrasound
}

\author{
Oscar Epis • Luca Giacomelli • Eleonora Bruschi
}

Published online: 27 April 2012

(C) Springer-Verlag 2012

\section{Erratum to: Rheumatol Int}

\section{DOI 10.1007/s00296-012-2403-7}

Panel D in Fig. 1 reports the data concerning specific rheumatology indications in the period 2001-2010 and not 1980-2010 as erroneously stated in the figure legend.

The online version of the original article can be found under doi:10.1007/s00296-012-2403-7.

O. Epis $(\bowtie) \cdot$ E. Bruschi

Rheumatology Unit, Niguarda Ca' Granda Hospital,

Piazza Ospedale Maggiore 3, 20162 Milan, Italy

e-mail: oscar.epis@ospedaleniguarda.it

L. Giacomelli

Free Researcher, Milan, Italy 